Т.М. Шумляева ${ }^{1}$, А.В. Дубовая ${ }^{1}$, И.П. Фролова², Ю.В. Коломойцева ${ }^{2}$, Л.Н. Кравцова², Е.Г. Гуренко ${ }^{1}$

${ }_{1}^{1} Г 00$ ВПО «Донецкий национальный медицинский университет имени М. Горького», Донецк

²Республиканская клиническая туберкулезная больница, Донецк

\title{
ОСЛОЖНЕННОЕ ТЕЧЕНИЕ ПЕРВИЧНОГО ТУБЕРКУЛЕЗНОГО КОМПЛЕКСА У РЕБЕНКА ДВУХ ЛЕТ
}

Первичный туберкулез у детей характеризуется скудностью клинической симптоматики [1]. Однако первичный туберкулезный комплекс (ПТК), относящийся к редким формам туберкулеза у детей, в большинстве случаев сопровождается клиническими проявлениями. Клинические проявления ПТК многообразны и зависят от различных факторов: возраста ребенка, наличия и качества проведенной вакцинации БЦЖ, состояния общей резистентности, выраженности морфологических изменений $[2,3]$. Первичный туберкулезный комплекс характеризуется острым началом заболевания с развитием следующих синдромов: туберкулезной интоксикации, бронхолегочного поражения и абдоминального синдрома [4]. Осложненное течение первичного туберкулеза формируется в случае сочетания нескольких факторов риска [5]. Первичному туберкулезному комплексу свойственны такие осложнения, как первичная каверна, казеозная пневмония, железистобронхиальный свищ, ателектаз. Одним из наиболее важных факторов риска развития осложненного течения первичного туберкулеза является возраст [6]. У детей раннего возраста чаще выявляют осложнения и неблагоприятные исходы заболевания, чем у детей старше 3-х лет. В статье описан клинический случай осложненного первичного туберкулеза у ребенка раннего возраста, который характеризовался стертой клинической картиной, отсутствием туберкулезной интоксикации и наличием лишь бронхолегочного синдрома, что вызвало трудности в постановке окончательного диагноза и ведении больного.

Больной Б., мальчик двух лет 10 месяцев, из малообеспеченной семьи, поступил в клинику после выявления изменений на рентгенограмме в связи с обследованием по поводу виража туберкулиновой пробы. Ребенок рожден от 4-й беременности, протекавшей на фоне многоводия, в роддоме вакциной БЦЖ не привит (мать
ВИЧ-инфицирована), вес при рождении - 2100 г. Родоразрешение проведено путем кесарева сечения, после рождения диагностирована анемия, неонатальная желтуха. Мальчик находился под наблюдением инфекциониста из-за перинатального контакта по ВИЧ-инфекции. В возрасте одного года 7 месяцев ВИЧ-статус был исключен и больной снят с учета. Болел ОРВИ более 3 раз в году, состоял на учете у педиатра в группе часто длительно болеющих детей (ЧДБ). В настоящее время наблюдается хирургом по поводу гемангиомы грудной клетки, нуждается в оперативном лечении.

Мальчик взят на учет фтизиатром 7 месяцев назад, когда была впервые выявлена положительная проба Манту с 2 TE папула 7 мм. После установления виража туберкулиновой пробы ребенку назначено химиопрофилактическое лечение, которое родственники отказались проводить. Месяц назад при повторном профилактическом обследовании на рентгенограмме у мальчика обнаружены изменения. Направлен на обследование и лечение в стационарное отделение Республиканской клинической туберкулезной больницы. При обследовании родителей у отца выявлен туберкулез легких, подтвержденный молекулярно-генетическим методом, обнаружена ДНК микобактерии туберкулеза с чувствительностью к рифампицину. Мать здорова. На момент поступления ребенка в отделение жалоб не было, при объективном осмотре патологии со стороны внутренних органов не обнаружено. Результаты обследования: проба Манту с 2 TE - папула 7мм (сохранялась пигментация 14 мм). В клиническом анализе крови патологических отклонений от нормы не выявлено, в клиническом анализе мочи - проте-

(c) Т.М. Шумляева, А.В. Дубовая, И.П. Фролова, Ю.В. Коломойцева, Л.Н. Кравцова, Е.Г. Гуренко, 2020 (c) Университетская Клиника, 2020 
инурия (белок-0,12г/л). Биохимический анализ крови соответствовал возрастной норме. В первые сутки поступления больного в стационар были исследованы промывные воды желудка молекулярно-генетическим методом Gene Xpert MTB/RIF. Обнаружена ДНК микобактерии туберкулеза с устойчивостью к рифампицину.

На обзорной рентгенограмме органов грудной клетки определялись: в нижней доле левого легкого - фокус затенения средней интенсивности, расширение тени левого корня за счет увеличенных лимфоузлов, в медиальных отделах легких - усиление легочного рисунка за счет сосудистого и интерстициального компонентов.

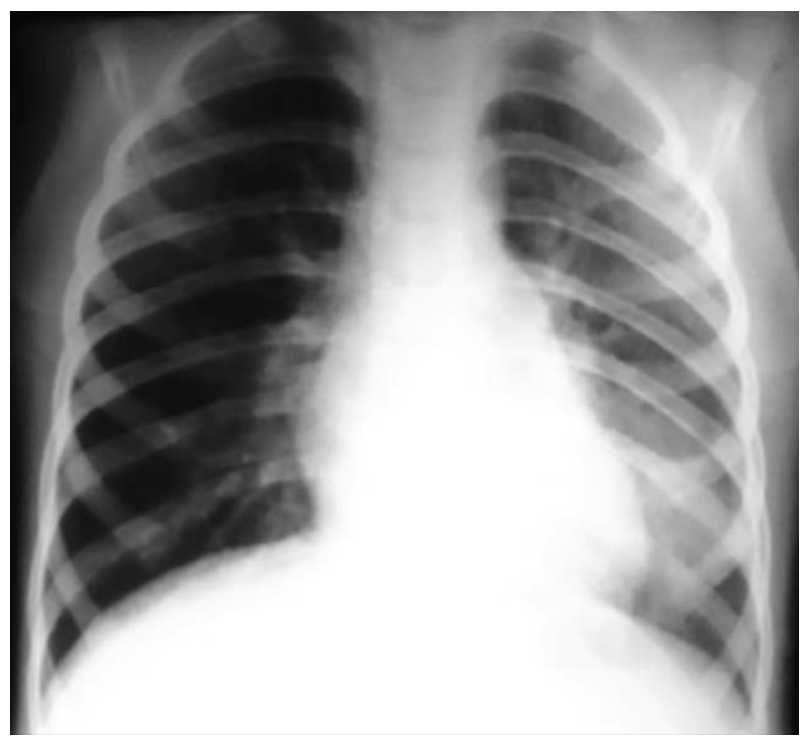

A
Изменения трактовались как первичный туберкулезный комплекс левого легкого (рис. 1.)

С учетом анамнеза жизни и заболевания, данных рентгенографического и молекулярногенетического исследования больному установлен диагноз: Риск мультирезистентного туберкулеза (вероятная устойчивость к изониазиду и рифампицину одновременно), первичный туберкулезный комплекс нижней доли левого легкого. Согласно весу ребенка назначена соответствующая схема лечения противотуберкулезными препаратами (ПТП): пиразинамид, канамицин, левофлоксацин, этионамид, циклосерин. Через 49 дней лечения у ребенка появился сухой кашель, на контрольной рентгенограмме отме-

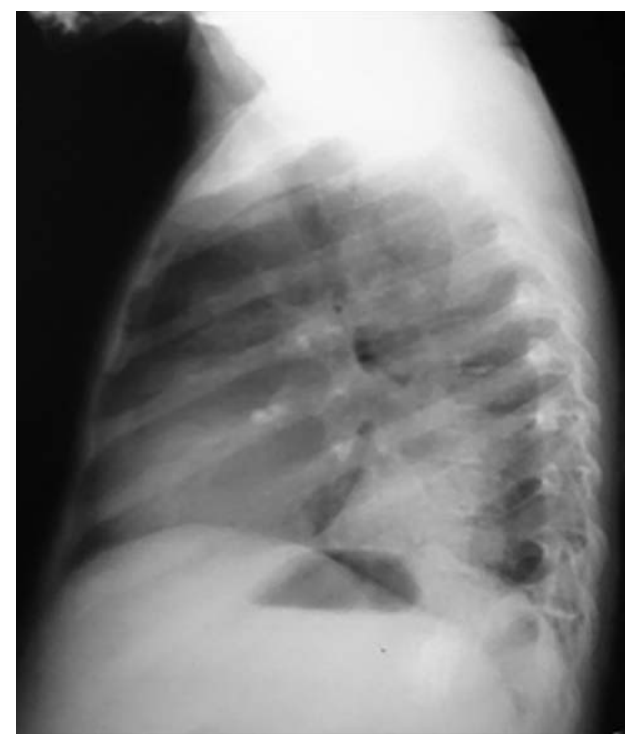

Б

Рис. 1. Рентгенограмма органов грудной клетки больного Б. на момент поступления в прямой (А) и боковой (Б) проекциях.

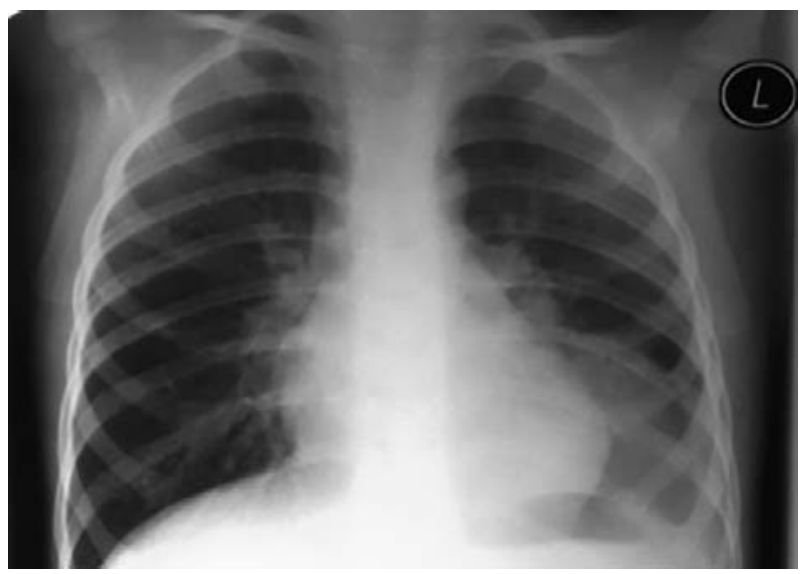

A

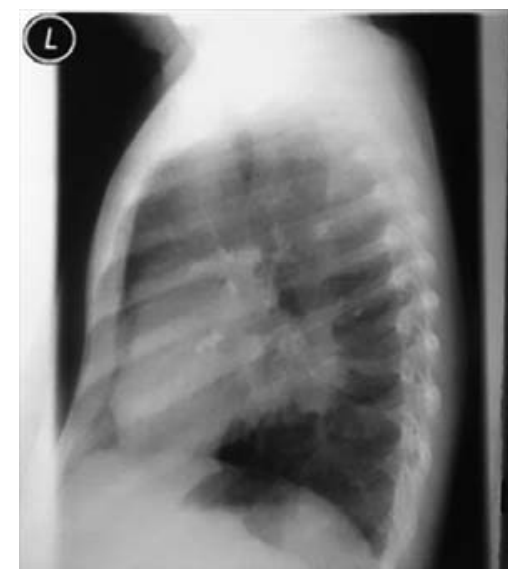

Б

Рис. 2. Рентгенограмма органов грудной клетки больного Б. через 2 месяца после начала лечения в прямой (А) и боковой (Б) проекциях. 
чена отрицательная динамика в виде нарастания ателектатически - воспалительных изменений (рис. 2.)

К этому времени в промывных водах желудка ребенка обнаружен рост микобактерий туберкулеза (МБТ) на жидкой среде Мидллбрука и твердой среде Левенштейна-Йенсена, чувствительность возбудителя к ПТП сохранена. Больному изменена схема лечения и назначены препараты первого ряда (изониазид, пиразинамид, рифампицин, этамбутол). Через 2 месяца лечения по новой схеме на контрольной рентгенограмме органов грудной клетки (ОГК) отмечено дальнейшее нарастание ателектатическивоспалительных изменений. Для определения дальнейшей тактики ведения ребенка был созван фтизиопедиатрический консилиум. Мальчику рекомендована бронхоскопия с диагностической целью (исключение других возможных причин ателектаза, в том числе инородного тела бронха.

В эндоскопическом отделении Республиканской детской клинической больницы была выполнена бронхоскопия. В просвете левого нижнедолевого бронха выявлено образование белесоватого цвета, полностью перекрывающее просвет бронха. При удалении образования отмечена его фрагментация, на месте удаленного материала слизистая оболочка бронха эрозирована, кровоточива. Материал отправлен на гистологическое исследование. В препаратах обнаружены обширные участки казеозного некро-

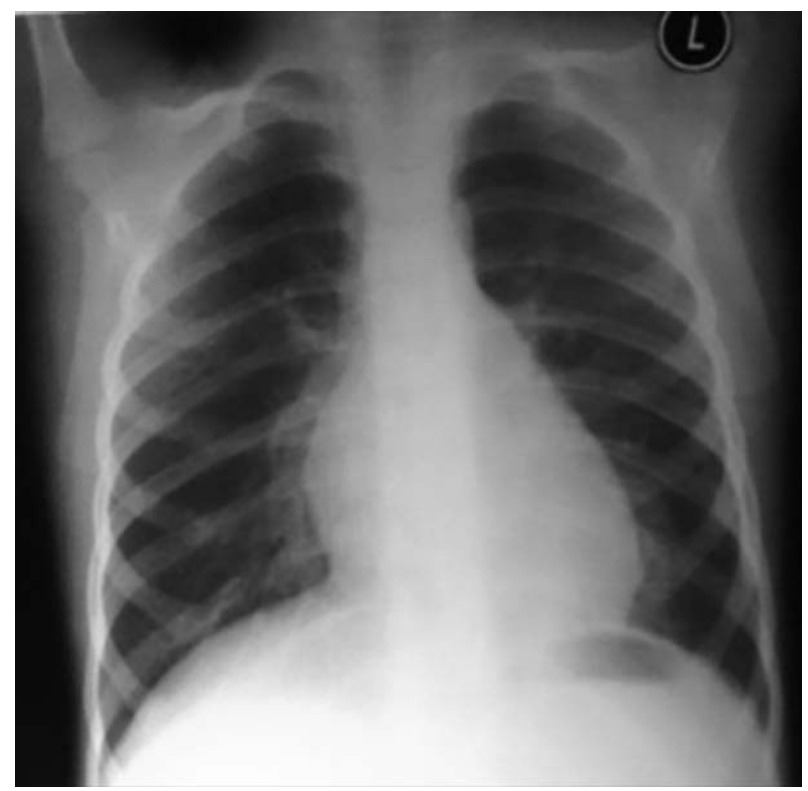

A за, обильная лимфоидная инфильтрация, наличие единичных эпителиоидных клеток, строящих гранулемы, характерные для туберкулезного процесса.

На основании полученных данных ребенку выставлен заключительный клинический диагноз первичного туберкулезного комплекса, осложненного эндобронхитом, ателектазом нижней доли левого легкого. Лечение препаратами первого ряда было продолжено до 4 месяцев (120 доз). По окончании интенсивной фазы лечения состояние ребенка нормализовалось: прекратился кашель, отмечалась положительная рентгенологическая динамика - уменьшение ателектатически-воспалительных изменений в нижней доле левого легкого, уменьшение лимфоузлов в левом корне; формирование фиброателектаза в S8 левого легкого (рис. 3.).

После завершения полного курса лечения на рентгенограмме сохранялись уплотненные лимфатические узлы в левом корне и фиброателектаз в S8 левого легкого.

Данный пример свидетельствует о сложности верификации диагноза при нетипичной клинической картине осложненного течения первичного туберкулезного комплекса. У больного, даже на фоне адекватной антибактериальной химиотерапии, на рентгенограмме определялось нарастание ателектатическивоспалительных изменений, что потребовало проведения диагностической бронхоскопии. Очевидно, в случае отсутствия положительной

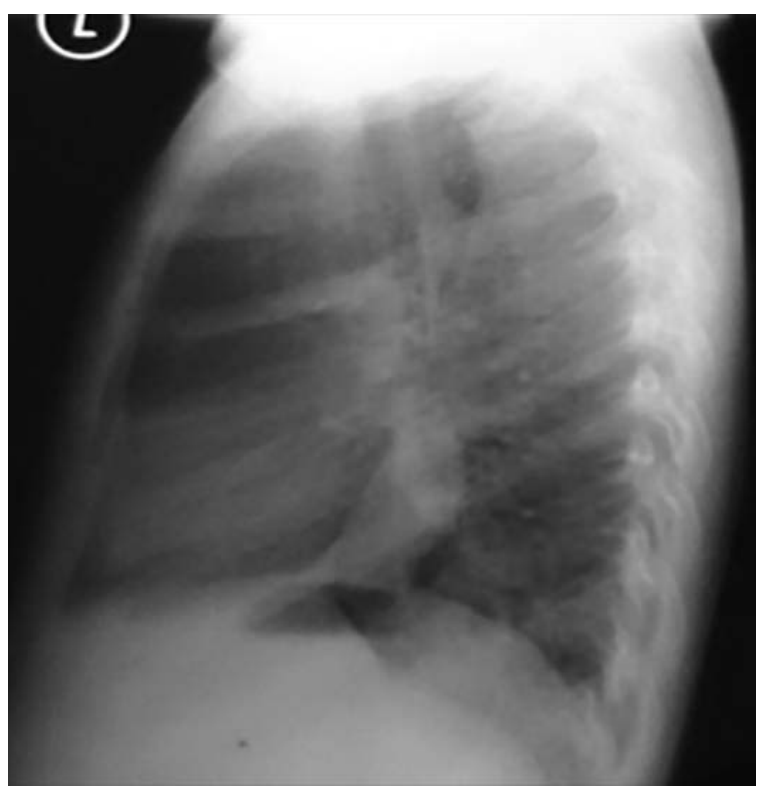

Б циях.

Рис. 3. Рентгенограмма органов грудной клетки больного Б. при выписке в прямой (А) и боковой (Б) проек- 
рентгенологической динамики бронхоскопия является важным методом, позволяющим своевременно диагностировать патологию в брон- хиальном дереве и избежать необратимых изменений в легочной ткани.

\section{Т.М. Шумляева ${ }^{1}$, А.В. Дубовая ${ }^{1}$ И.П. Фролова ${ }^{2}$ Ю.В. Коломойцева ${ }^{2}$, Л.Н. Кравцова ${ }^{2}$ Е.Г. Гуренко}

${ }^{1}$ ГОО ВПО «Донецкий национальный медицинский университет имени М. Горького», Донецк

${ }^{2}$ Республиканская клиническая туберкулезная больница, Донецк

\section{ОСЛОЖНЕННОЕ ТЕЧЕНИЕ ПЕРВИЧНОГО ТУБЕРКУЛЕЗНОГО КОМПЛЕКСА У РЕБЕНКА ДВУХ ЛЕТ}

Представлен случай осложненного первичного туберкулеза у мальчика 2-х лет, родившегося от ВИЧинфицированной матери. Прогрессирующее течение заболевания у ребенка, отмеченное на фоне множества факторов риска, вызвало трудности диагностики и сложности в лечении первичного туберкулеза.
Только полное комплексное обследование ребенка с использованием бронхоскопии позволило подтвердить диагноз

Ключевые слова: первичный туберкулезный комплекс, эндобронхит, ателектаз, фибробронхоскопия, дети.

\section{T.M. Shumlyaeva ${ }^{1}$, A.V. Dubovaya ${ }^{1}$, I.P. Frolova ${ }^{2}$, Yu.V. Kolomoytseva ${ }^{2}$, L.N. Kravtsova ${ }^{2}$, E.G. Gurenko ${ }^{1}$}

${ }^{1} S E I H P E \ll M$. Gorky Donetsk National Medical University», Donetsk

${ }^{2}$ Republican Clinical Tuberculosis Hospital, Donetsk

\section{COMPLICATED COURSE OF THE PRIMARY TUBERCULOUS COMPLEX IN A 2-YEAR-OLD CHILD}

The case of complicated primary tuberculosis in a 2 -year-old boy is presented. The boy born to an HIVinfected mother. The progressive disease course in the child, noted against the background of many risk factors, caused diagnostic difficulties and difficulties in the treat- ment of primary tuberculosis. Only a complete physical examination of the child, using bronchoscopy allowed to confirm the diagnosis.

Key words: primary tuberculous complex, endobronchitis, atelectasis, bronchoscopy, children.

\section{ЛИТЕРАТУРА}

1. Норейко Б.В. Ранний период туберкулезной инфекции у детей. Здоровье ребенка. 2008; 5 (14): 132-134.

2. Норейко Б.В., Шумляева Т. М., Кириллова Т. В. Первичный туберкулезный комплекс. Здоровье ребенка. 2009; 3: $83-85$.

3. Старшинова А.А., Павлова М.В., Довгалюк И.Ф., Овчинникова Ю.Э., Ялфимов А.Н. Влияние факторов риска на развитие и течение туберкулезной инфекции у детей из семейного контакта в современной социальноэпидемической ситуации. Проблемы туберкулеза и болезней легких. 2010; 6: 34-39.

4. Лепшина С. М., Пустовой Ю. Г., Миндрул М. А., Корж Е. В., Гуренко Е. Г., и др. Туберкулез у детей и подростков: уч.пособие. Луганск: издательство «Elton»; 2017. 268.

5. Норейко Б.В., Шумляева Т. М. Факторы риска развития осложненного течения туберкулеза у подростков. Вестник гигиены и эпидемиологии. 2010; 14 (2): 322-324.

6. Губкина М. Ф., Овсянкина Е. С. Основные факторы риска развития туберкулеза у детей и подростков. Проблемы туберкулеза и болезней легких. 2005; 1:10-20.

\section{REFERENCES}

1. Norejko B.V. Rannij period tuberkuleznoj infekcii u detej [Early period of tuberculosis infection in children]. Zdorov'e rebenka. 2008; 5 (14): 132-134 (in Russian).

2. Norejko B.V., Shumlyaeva T. M., Kirillova T. V. Pervichnyj tuberkuleznyj kompleks [Primary tubercular complex]. Zdorov'e rebenka. 2009; 3: 83-85 (in Russian).

3. Starshinova A.A., Pavlova M.V., Dovgalyuk I.F., Ovchinnikova Yu.E., YAlfimov A.N. Vliyanie faktorov riska na razvitie i techenie tuberkuleznoj infekcii u detej iz semejnogo kontakta v sovremennoj social'no-epidemicheskoj situacii [Influence of risk factors on the development and course of tuberculosis infection in children from family contact in the present-day socioepidemiological situation]. Problemy tuberkuleza i boleznej legkih. 2010; 6: $34-39$ (in Russian).

4. Lepshina S. M., Pustovoj YU. G., Mindrul M. A., Korzh E. V., Gurenko E. G., i dr. Tuberkulez u detej i podrostkov: uch. posobie [Tuberculosis in Children and Adolescents: Training Manual]. Lugansk: izdatel'stvo «Elton»; 2017. 26839 (in Russian).

5. Norejko B.V., SHumlyaeva T. M. Faktory riska razvitiya oslozhnennogo techeniya tuberkuleza u podrostkov [Risk factors for developing a complicated course of tuberculosis in adolescents]. Vestnik gigieny i epidemiologii. 2010; 14 (2): 322-324 (in Russian).

6. Gubkina M. F., Ovsyankina E. S. Osnovnye faktory riska razvitiya tuberkuleza u detej i podrostkov [Main risk factors for tuberculosis in children and adolescents]. Problemy tuberkuleza i boleznej legkih. 2005; 1:10-20 (in Russian). 